\title{
Obesity Management in Primary Health Care: Front-Line Providers' Experiences and Views
}

\author{
Hatem Al-Saadi, Haya Malallah, Jameela Al-Saadi, Narjis AlSheala, Abdullah Al-Balushi, Said Al-Abri, \\ and Tariq Al-Saadi
}

\section{ABSTRACT}

\begin{abstract}
As in the rest of the world, obesity in Oman has increased and according to World Health Organization (WHO) data, prevalence of obesity in 2008 and 2016 were $20.9 \%$ and $27 \%$ respectively. This study explores primary care physicians' current strategies and management of obesity, attitude and perceptions towards obesity, educational needs, and their views on long-term follow up.
\end{abstract}

\begin{abstract}
Methods: A cross sectional study was conducted where practicing family medicine physicians from different governorates were invited to participate in an online questionnaire-based survey. Participant were invited via email and responses were kept anonymous. Responses were collected over three weeks in April 2019 and only responses that met inclusion criteria were analyzed with SPSS v22.
\end{abstract}

Results: 77 complete responses met inclusion criteria and female were the majority $(67.5 \%)$. Half of participants had less than 10 years of experience. Weight and BMI were recorded routinely by two-thirds of participants whereas waist- hip ratio was recorded by only $12 \%$. Weight reduction medications were prescribed by $5.2 \%$ and $24 \%$ would refer an obese patient to Bariatric center. Main barrier to obesity management and referral was inadequate obesity specialist centers followed by short consultation times. The pathophysiology mechanism of obesity and related hormones was only known by $\mathbf{4 0 . 8 \%}$. Almost all participants agreed that formal obesity management training should be integrated as part of residency training.

Conclusion: Despite the significant number of comorbidities related to obesity and its complications, weight, BMI and other anthropometric measures were not routinely performed. Nationally, the rate of referral to bariatric centers for evaluation is low. Boundaries and challenges do exist and need to be addressed. Obesity and weight management need to be integrated as part of Family Physicians Training Program.

Keywords: Obesity, Primary care, Family Physicians, weight management, Obese patients.

\section{INTRODUCTION}

Obesity has become a common global health problem affecting males and female of all age [1]. The World Health Organisation (WHO) defines obesity as a body mass index (BMI) of $\geq 30 \mathrm{~kg} / \mathrm{m}^{2}$. It is associated with diabetes, hypertension, arthritis, obstructive sleep apnoea, high cholesterol, and other chronic health conditions [2]. However, sustained weight loss is associated with preventions, resolution, or alleviation of many of these health conditions.

As in the rest of the world, obesity in Oman has increased and according to WHO data, prevalence of obesity in 2008 and 2016 were $20.9 \%$ and $27 \%$ respectively [3]. A statement by the Ministry of Health in the First Oman Obesity
Published Online: November 13, 2020

ISSN: 2593-8339

DOI: $10.24018 /$ ejmed.2020.2.6.549

\section{Hatem Al-Saadi *}

Gulf Research Collaboration Group, University Hospitals of North Midlands, United Kingdom.

(e-mail: dr.hdhy@gmail.com)

Haya Malallah

Ministry of Health, Kuwait.

Jameela Al-Saadi

Ministry of Health, Sultanate of Oman.

Narjis AISheala

College of Medicine \& Health Science, National University of Science \& Technology, Sultanate of Oman.

Abdullah Al-Balushi

Department of Pharmacy, Oman College of Health Sciences, Sultanate of Oman. Said Al-Abri

Statistical Researcher, Center for Government Communications, General Secretariat to the Cabinet, Sultanate of Oman.

Tariq Al-Saadi

Montreal Neurological Institute and Hospital, McGill University, Canada.

*Corresponding Author
Conference in 2018 stated that "The prevalence rate of overweight and obesity in the sultanate was about $60 \%$ of total adult population"' [4].A recent population-based survey (STEPS Survey 2017) by the Centre of Studies and Research with collaboration with Ministry of Health in Oman on noncommunicable disease and their risk factors showed that total percentage of overweight and obesity were $35.5 \%$ and $30.7 \%$ respectively [5].

Primary health care providers, Family medicine Physicians/ General Practitioners (GPs) and allied health care professionals, are the front-line health providers who are highly involved in preventing and managing health problems. They provide the framework for delivering weight management through counselling, identifying underlying causes of obesity, preventing, and treating obesity [6]. Some 
concerning trends have been found on the literature on the investigation of GPs attitudes, perceptions, and barriers to address obesity. The most common view is that weight management is un-rewarding and the belief that the treatment is unsuccessful [7]. A study by Huang et al reported barriers to primary health care providers to give weight management advice include lack of time, knowledge/ suboptimal training, limited resources, and insufficient confidence [8]. However, the general consensus is that Family Medicine Physicians play important role in obesity management and it is unclear if whether international findings can be applied in Oman.

A number of international studies have evaluated GPs perceptions and opinion for weight management interventions, but to date there have been no studies conducted in Oman [7], [8]. This study explores the primary care physicians' current strategies and management of obesity, attitude and perceptions of GPs, educational needs, GPs views on long-term follow up.

\section{METHODS}

Review of the literature has been conducted and previous studies have been identified and analyzed. A cross-sectional study was conducted in April 2019 by distributing a survey on Family Medicine/ GPs Perceptions on Obesity and Weight Management in the Primary Health Care. Data collection was open for three weeks. Elements of the survey were developed according to the objectives of the study to explore implementation of the 5As of obesity prevention and management which are shown in Fig. 1.

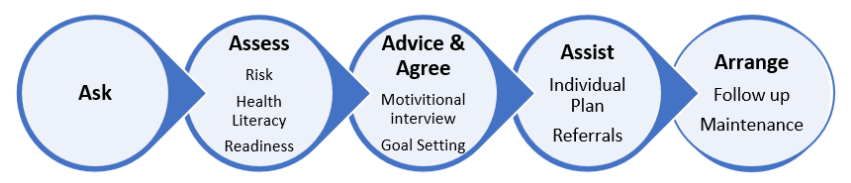

Fig. 1. 5As of weight management and prevention covered by the survey.

The survey was designed with seven themes were 3 and 5point Likert-scales were used, in which the participants had to indicate their level of agreement with each statement by selecting one from 'strongly agree', 'agree', 'neutral', 'disagree' or 'strongly disagree'; or, in practice statements, from 'all of the time', 'most of the time', or 'occasionally'. For the education and training theme, 'Yes' or 'No' question type was used. The survey was then validated with a group of doctors and amendments and corrections were performed accordingly.

Survey Themes:

A) Demographics.

B) Current Strategies.

C) Knowledge Perceptions.

D) Medical Management.

E) Bariatric Surgery.

F) Barriers to management and limitations to referrals.

G) Education and Training.

The survey was distributed randomly across different primary health centers and polyclinics within the sultanate. Private hospitals and centers were excluded. Informed written consents were obtained from all participating physicians prior starting the survey and responses were anonymous. Collected data that met inclusion criteria were entered and analysis with the Statistical Package for Social Sciences (IBM SPSS v22). Data were described as mean, frequencies or percentages. Parametric tests were used assess associations and significance differences between variables with the use of Chi square test. A p-value of $<0.05$ was considered statistically significant.

\section{RESULTS}

\section{A. Demographics}

Total received completed responses that met inclusion criteria were 77 of which 25 were males and 52 were females ( $32.5 \%$ and $67.5 \%$ respectively). With regard to experience in GP practice, $53.25 \%$ had less than 10-years' experience. Majority of participants were from Al Batinah North Governorate followed by South Al Batinah and Muscat (33.8\%, 23.4\%, and $22.1 \%$ respectively). Participant characteristics are shown in Table 1.

TABLE 1. PARTICIPANTS CHARACTERISTICS

\begin{tabular}{|c|c|c|}
\hline \multicolumn{3}{|c|}{ Participant Characteristics $(n=77)$} \\
\hline \multirow[t]{4}{*}{ Age } & 25-34 Years & 23 \\
\hline & 35-44 Years & 40 \\
\hline & 45-54 Years & 13 \\
\hline & 55-64 Years & 1 \\
\hline \multirow[t]{2}{*}{ Gender } & Male & 25 \\
\hline & Female & 52 \\
\hline \multirow{6}{*}{ Years in GP Practice } & 1-3 Years & 8 \\
\hline & 4-6 Years & 9 \\
\hline & 7-10 Years & 24 \\
\hline & 11-14 Years & 20 \\
\hline & 15-19 Years & 10 \\
\hline & $>20$ Years & 6 \\
\hline \multirow{8}{*}{ Region/Governorate } & Al Dakhliah & $3(3.9 \%)$ \\
\hline & Al Batinah North & $26(33.8 \%$ \\
\hline & Al Batinah South & $18(23.4 \%)$ \\
\hline & Al Dhahirah & $4(5.2 \%)$ \\
\hline & Al Sharqiah & $3(3.9 \%)$ \\
\hline & Musandam & $1(1.3 \%)$ \\
\hline & Muscat & $17(22.1 \%)$ \\
\hline & Skipped question & $5(6.5 \%)$ \\
\hline
\end{tabular}

Overall, $70.1 \%$ of the participants see more than 60 patients per week (Fig. 2). At the same time, overweight and obese patients are seen in all primary health care and account for a significant percentage of patient seen by primary healthcare providers as shown in Fig. 3.

Percentage

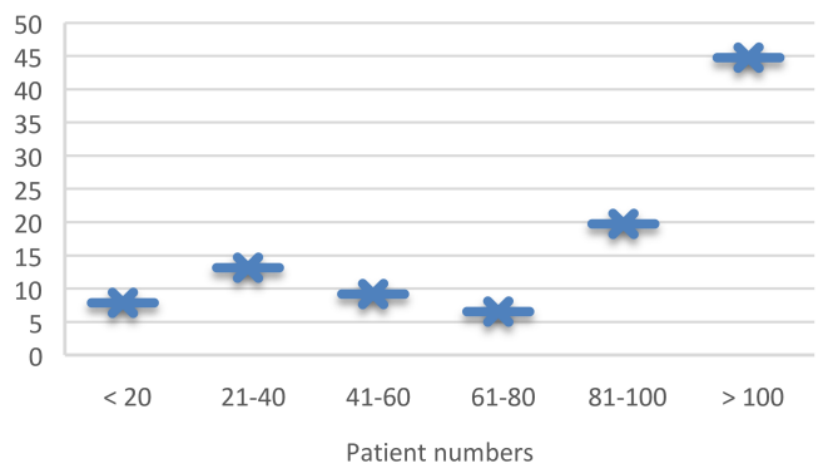

Fig. 2. Percentages of total number family physicians and number of patients seen per week. 


\section{Percentage of obese patients seen per week}

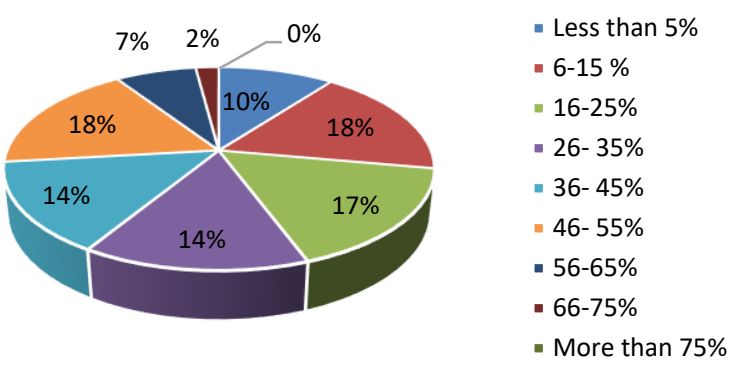

Fig. 3. Percentages of overweight and obese patients seen per week.

\section{B. Current Strategies of Weight Management}

A $66.23 \%$ of the GPs record patient's weight $(\mathrm{Kg})$ and BMI in most of the time as part of patient's management $(29.87 \%$ occasionally and $3.9 \%$ not at all). Hip to waist ratio is a quick measure of fat distribution that may help indicate a person's overall health. In our study, hip: waist ratio was not measured at all by $53.25 \%$ (35\% occasionally, $11.69 \%$ most of the time). Leaflets and educational materials were provided occasionally by $59.74 \%$ (28.57\% not at all, 11.69 most of the time).

\section{Perceptions and Attitudes}

Obesity has been perceived as a big health problem requiring urgent action by $88.31 \%$ (n 68) and $70.13 \%$ believe that obesity is due to lack of control and patients are primarily responsible for their weight. The majority of participants were aware of NICE guideline for bariatric surgery referrals $(63.64 \%)$ and $58.44 \%$ feel confident in their ability to treat obese patients. Of the total responders, $70.13 \%$ would offer advice about weight control to obese patients without patient asking. A similar percentage of responders believe primary healthcare providers have a role in obesity management. However, only $37.66 \%$ of GPs consider the treatment of obesity in their centers as effective.

\section{Medical Management}

In our study, $42.85 \%$ of Family Medicine Physicians feel confident in prescribing pharmacotherapy to treat obesity. However, only $5.19 \%$ often prescribe weight management medications. Referral to behavioral modification for weight reduction seems popular between participants were $72.73 \%$ of GPs refer their patients.

\section{E. Bariatric Surgery}

National bariatric surgery centers were known by $71.43 \%$ of Family Physicians in this study, and $50.65 \%$ are aware of different bariatric procedures and feel confident in discussing them with their patients. However, only $24.67 \%$ of responders agree that overweight and obese patient should be referred to bariatric surgery. Bariatric surgery has been affirmed effective and safe with positive long-term outcomes by $57.14 \%$. Majority of Family Physicians (70.13\%) agree that post bariatric follow up should be lifelong for early detection and management of complications.

\section{F. Barriers to Management and Limitation for Referrals}

The inadequate number of obesity management centers across the country has been perceived as the commonest barrier to management and limitation to referral for bariatric surgery $(83.11 \%)$ with average weighted score of 4.14 . This was followed by short consultation time due to large patients' volume and work overload $(76.63 \%)$. Inadequate training in providing lifestyle and behavioral counselling for obese patients was seen as one of the top barriers (71.43\%). Lack of special obesity clinic to refer patients has been agreed to be another limiting factor by $59.74 \%$. Lack of awareness about bariatric surgery and its benefit was seen as a factor by $50.65 \%$, whereas lack of national guidelines accounted for $48.06 \%$. Concern of post op follow up as a barrier for referral has been perceived by $61.04 \%$ of GPs. $58.44 \%$ of respondents disagreed that bariatric surgery has limited benefit or high complications. Weighted average scores for Barriers to management are shown in table 2 .

TABLE 2: WEIGHTED AVERAGE SCORES FOR BARRIERS TO MANAGEMENT

\begin{tabular}{lc}
\multicolumn{1}{c}{ AND REFERRALS } \\
\hline \multicolumn{1}{c}{$\begin{array}{c}\text { E. Barriers to Management and Limitations for } \\
\text { Referrals }\end{array}$} & Average Score \\
\hline $\begin{array}{l}\text { Consultation time with patient is short due to } \\
\text { patients' volume and work overload } \\
\text { There is lack of special obesity clinic to refer } \\
\text { patients to }\end{array}$ & 3.03 \\
$\begin{array}{l}\text { There is lack of nationally adopted guidelines for } \\
\text { management of obesity }\end{array}$ & 3.61 \\
$\begin{array}{l}\text { The number of obesity management centres across } \\
\text { the country is inadequate }\end{array}$ & 4.14 \\
$\begin{array}{l}\text { Inadequate training in providing lifestyle and } \\
\text { behavioural counselling for obese patient }\end{array}$ & 3.71 \\
$\begin{array}{l}\text { Lack of Awareness about bariatric procedure and } \\
\text { its benefits }\end{array}$ & 3.34 \\
$\begin{array}{l}\text { Concern with follow up post discharge } \\
\text { Bariatric surgery has limited benefits with high } \\
\text { complication rate }\end{array}$ & 3.55 \\
\hline
\end{tabular}

\section{G. Education and Training}

Of the total responders, only $27.27 \%$ have attended a course or formal meeting in obesity management in the last 6 months. Almost all responders $(97.40 \%)$ think that formal weight and obesity management education should be integrated as part of Family Medicine training. Another high percentage of responders $(96.10 \%)$ agreed that they should be obesity management GP Specialists in each Health centers. There was a lack of understanding of the pathophysiology and knowledge of which hormone is responsible for increasing appetite were only $40.79 \%$ answered correctly. The most common suggested long-term follow up post discharge from bariatric surgery center was by Family Physicians followed by Dietitians, $67.53 \%$ and $19.48 \%$ respectively, as shown in Fig. 4.

\section{Post Op follow up}

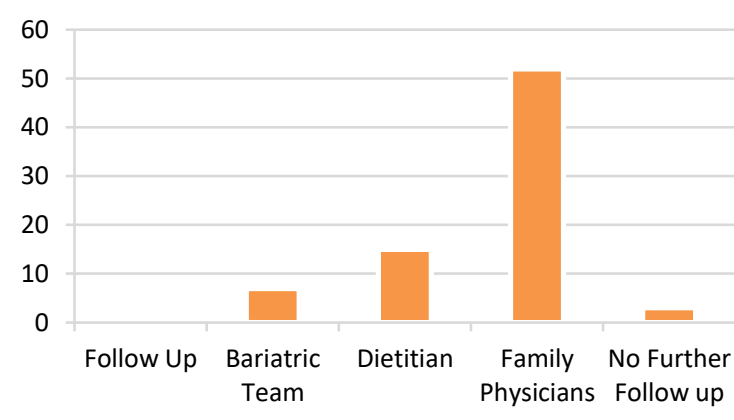

Fig. 4. Perception on post op follow up. 


\section{DisCUSSION}

Obesity is a problem increasing globally and the number of patients seeking medical help is increasing as well with resultant increased constrain in global health resources [9], [10]. Primary healthcare professionals are arguably the best health professionals positioned to address obesity and its related issues since they are the front-line service providers. Worldwide, several studies have evaluated and discussed primary healthcare providers perceptions and attitudes towards obesity and weight management [7], [8], [11], [15], [16]. However, to date there has been no study addressed this in Oman. This study explores the current primary healthcare providers strategy for obesity management and evaluates their attitudes and perceptions towards obesity management.

Findings of this study showed that about one quarter of patients seen in primary health care centers were obese (26\%). Body Mass Index (BMI) is a widely used measurement in outpatient clinic. The study found that two thirds of family physicians recorded weight and BMI of their patients in most of the time. A survey by Smith et al showed that less than $50 \%$ of physicians recorded weight and/or BMI of their patients [11]. Current American, Canadian and European obesity assessment and management guidelines recommend measuring weight and BMI as first step to evaluate obesity in adult and pediatric individuals [12], [13]. Despite the significance of waist: hip ratio as a surrogate marker for obesity that can predict associated complications [14], such measurement was performed routinely by only $11.7 \%$ of family physicians.

Primary healthcare providers have a major role in prevention, diagnosis and management of obesity [15]. This can be achieved in the form of education, prescribing medical therapy or referral to appropriate health disciplines. Despite the importance of such actions, Foster et al found that obesity and related conditions were addressed inconsistently at consultations [16]. However, the same study [11] found that $70 \%$ of physicians prescribed pharmacological treatment for obesity comparing to $5.19 \%$ our study. In our study, participants who believe they are confident in treating patients with obesity believe that the weight management in their center is effective ( $p$ 0.02). Behavioral therapy combined with diet and physical activity are effective weight management interventions [17]. The longer the period of engagement with this intervention the better the outcomes [18]. Our results showed that about three quarters of primary care physicians refer patients to behavioral modification therapy.

Bariatric surgery is the most effective treatment for patients with obesity with long lasting results [19]. The health improvements experienced by a typical bariatric patient are reflected in cost savings to the healthcare system. Despite the clear and widely documented benefits of bariatric surgery, stigma surrounding the procedure still exists [20]. Smith et al [11] reported that $86 \%$ of physicians have referred patients for bariatric centers for evaluation. Another study reported that only $15 \%$ of patients with morbid obesity were referred to bariatric surgery [21]. Our results showed only about one quarter of primary healthcare physicians refer patients with obesity to bariatric centers for surgical interventions.

The top two barriers to obesity management and referral to specialist centers were limited number of obesity management centers and short consultation time which were similar to other studies in the literature [22]-[24]. Foster et al, (2003) found that lack of knowledge on the effectiveness of bariatric interventions is another factor [16]. However, this has the lowest barrier score in our study. Since primary health care providers family physicians are at the front lines of obesity management, it is especially important to understand their opinions and familiarity with bariatric procedures and postoperative care. This is imperative in order to identify knowledge gaps and ensure that this beneficial treatment is being offered to those who needs it. More than two-thirds of participants were aware of the national bariatric centers and $50 \%$ were aware and confident of discussing with patients the different bariatric procedures offered nationally.

Early follow up post bariatric surgery is done by the bariatric team (surgeons, dietitians, and nurse specialist). However, post discharge from bariatric clinic there is no formal globally standardized follow up for these patients. The NICE guidelines recommend that after discharge from bariatric service, patients should have annual monitoring of nutritional status and supplements according to post- surgical need [25]. Currently, there is no mechanism on how this follow up can be implemented. Despite the international guidelines on post- bariatric follow up, there is no clear agreed census on long term follow up plans. There are concerns with long term follow up in the community with local GPs with regard to their experience with post bariatric patients, facilities and availability of resources [24]. Participants in our study agreed that follow up post bariatric surgery should be lifelong (70\%) and about a similar percentage believed this follow up should be with primary healthcare physicians.

Inadequate training in providing lifestyle and behavioral counselling for obese patient is considered the third barrier to obesity management and to referral to bariatric center. A formal weight and obesity management training integrated as part of family medicine training curriculum has been agreed by seventy- five family physicians accounting for $(97.4 \%)$ of the participants. Less than one third of the participants has attended a course or a formal meeting on obesity management within the last 6 months of the survey date. A survey conducted among 290 family physicians in the United States by the STOP Alliance and Harris Interactive survey reported that about $80 \%$ had no training in obesity management [27]. Kushner et al (2016) found that few questions were included in the United States Medical Licensing Examination (USMLE) that addressing obesity managements and its related conditions [28].

There is a lack of understanding of obesity and the pathophysiology of related hormones. To study the relationship between attending a meeting or a course on obesity management and the hormone responsible for appetite, responses were categorized into 2 groups. Total number of true answers was 31 and 9/31 have attended meetings before. With regards to years in practice, $61.3 \%$ of the correct answers were for participants with less than 10 years' experience. Of the respondents with true answers, 12 of them were less than 35 years old ( $p>0.05)$. Most of the respondents who answered correctly see more than 40 patients a week (29/31). 
This current study has some limitations. As the study was cross sectional study, data cannot be collected over period of time to analyze behaviors changes and perceptions on current practice were personal reflections which might not represent the actual situation. The sampling method was based on the use of an online questionnaire in which participants were selected randomly and did not represents all governorates equally. Although this current study showed significant findings, the sample size was small.

Future research in the field of obesity prevention and management in the primary healthcare will be increasingly important to meet the increasing number of patients seeking medical help.

\section{RECOMMENDATIONS}

Based on the findings of this study, we recommend integrating obesity and weight management as part of Family Medicine Residency program to equip new graduates with the training required to deal with obesity and related comorbidities. Along this, annual meetings or Family Medicine Physician's Day to provide an update on obesity management. Establishment of Specialist Weight Clinic in different governorates is also recommended to facilitate accessible and high standard service.

\section{CONCLUSION}

Obesity is a globally increasing problem with modifiable chronic related conditions that necessitate appropriate management and preventive measures. Weight and BMI are not routinely performed in primary care. There is low referral rate to bariatric centers where lack of obesity management centers and limited consultation time were perceived as top reasons. These factors need to be addressed to improve service delivery. Along this there is also lack of knowledge on obesity and its related pathophysiology. Training and education as part of in-residency training and continuing professional education, for those in practice, is required. For better outcomes, obesity prevention and management service delivery require a wide systematic approach targeting all disciplines involved with appropriate use of resources.

\section{REFERENCES}

[1] WHO Fact Sheet, Obesity and Overweight, $1^{\text {st }}$ April 2020 (2020) Available sheets/detail/obesity-and-overweight

[2] National Health and Medical Research Council (NHMRC). National Health and Medical Research Council Clinical practice guidelines for the management of overweight and obesity in adults, adolescents and children in Australia. In: ed. Melbourne: National Health and Medical Research Council, 2013. Available at: https://www.omanobserver.om/omans-first-conference-on-obesity/

[3] Knoema, World Data ATLAS (2016). Available at: https://knoema.com/atlas/Oman/Female-obesity-prevalence

[4] MOH, $1^{\text {st }}$ Oman Obesity Conference, Media Center 20/10/2018. Ministry of Health, Oman. (2018) https://www.moh.gov.om/en/-/--835

[5] Oman STEP Survey, centre of Studies and Research, Ministry of Health, Oman (2017). Available at: https://mohcsr.gov.om/wpcontent/uploads/2018/12/Fact-Sheet-1-Omani-Non-Omani-18.pdf

[6] AljoudiA, Mwanri L, Al Dhaifallah A (2015) Childhood obesity in Saudi Arabia: Opportunities and challenges. Saudi Journal of Obesity, 3(1): 2-7.
[7] Alexander SC, Ostbye T, Pollak KI, Gradison M, Bastian LA, Brouwer RJN. Physicians' beliefs about discussing obesity: results from focus groups. Am. J. Health Promot. 2007;21(6):498-500.

[8] J. Huang, H. Yu, E. Marin, S. Brock, D. Carden, T. Davis, Physicians weight loss counseling in two public hospital primary care clinics, Acad. Med. 79 (2) (2004) 156-161.

[9] Ng M, Fleming T, Robinson M, et al. Global, regional, and national prevalence of overweight and obesity in children and adults during 1980-2013: a systematic analysis for the Global Burden of Disease Study 2013. Lancet. 2014; 384: 766-781

[10] Stevens G, Global health risks: progress and challenges. Bull World Health Organ. 2009; 87: 646

[11] Smith AW, Borowski LA, Liu B, et al. U.S. primary care physicians' diet-, physical activity-, and weight-related care of adult patients. Am J Prev Med 2011; 41:33-42.

[12] Yumuk V, Tsigos C, Fried M, Schindler K, Busetto L, Micic D, et al.; Obesity Management Task Force of the European Association for the Study of Obesity. European guidelines for obesity management in adults. Obes Facts. 2015;8(6):402-424.

[13] Lau DCW, Douketis JD, Morrison KM, Hramiak IM, Sharma AM, Ur E; Obesity Canada Clinical Practice Guidelines Expert Panel. 2006 Canadian clinical practice guidelines on the management and prevention of obesity in adults and children [summary]. CMAJ. 2007;176(8): S1-S13

[14] Zazai R, Wilms B, Enst B, Thunheer M, Schultes B. Waist Circumfrence and related anthropometric indices are associated with metabolic traits in severely obese subjects. Obes Surg. 2013;24(5): 777-782. Doi:10.1007/s11695-013-1141-6.

[15] Sturgiss, E, Elmitt, N, Haesler, E et al 2018, 'Role of the family doctor in the management of adults with obesity: a scoping review', BMJ Open, vol. 8, no. 2, pp. 1-29.

[16] Foster GD, Wadden TA, Makris AP, Davidson D, Sanderson RS, Allison DB, et al. Primary care physicians' attitudes about obesity and its treatment. Obes Res. 2003;11(10):1168-77.

[17] Shaw KA, O’Rourke P, Del Mar C, Kenardy J. Psychological interventions for overweight or obesity. Cochrane Database Syst Rev. 2009; 2:CD003818.

[18] Ahern AL, Wheeler GM, Aveyard P, Boyland EJ, Halford JCG, Mander AP, et al. Extended and standard duration weight-loss programme referrals for adults in primary care (WRAP): a randomised controlled trial. Lancet. 2017 Jun 3;389(10085):2214-2225. doi 10.1016/S0140-6736(17)30647-5. Epub 2017 May 3. Erratum in: Lancet. 2017 Jun 3;389(10085):2192. PMID: 28478041; PMCID PMC5459752.

[19] Colquitt, J., Picot, J., Loveman, E., Clegg, A., Surgery for obesity. Cochrane Database Syst Rev. 2009;2:CD003641.

[20] Sikorski C, Luppa M, Dame K, Brähler E, Schütz T, Shang E, et al. Attitudes towards bariatric surgery in the general public. Obes Surg. 2013 Mar; 23(3):338-45. doi: 10.1007/s11695-012-0767-0. PMID 22983771.

[21] Avidor Y, Still CD, Brunner M, Buchwald JN, Buchwald H. Primary care and subspecialty management of morbid obesity: referral patterns for bariatric surgery. Surg Obes Relat Dis. 2007;3(3):392-407.

[22] Hiddink GJ, Hautvast JG, van Woerkum CM, Fieren CJ \& van `t Hof MA (1995): Nutrition guidance by primary-care physicians: perceived barriers and low involvement. Eur. J. Clin. Nutr. 49, $842 \pm 851$.

[23] Aveyard P, Lewis A, Tearne B, Hood K, Christian-Brown A, Adab P, $\mathrm{Begh} \mathrm{R}$, et al. Screening and Brief intervention for obesity in primary care: a parallel, two-arm, randomised trial. The Lancet Lancet 2016; 388: 2492-500. http://dx.doi.org/10.1016/ S0140-6736(16)31893-1.

[24] Tsai AG, Histon T, Kyle TK, Rubenstein N, Donahoo WT. Evidence of a gap in understanding obesity among physicians. Obes Sci Pract. 2018;4(1):46-51. Published 2018 Jan 12. doi:10.1002/osp4.146.

[25] NICE Obesity: identification, assessment and management of overweight and obesity in children, young people and adults; Available at: $\quad$ http://www.nice.org.uk/guidance/cg189/chapter/1recommendations.

[26] Moyer VA. Screening for and management of obesity in adults: U.S Preventive Services Task Force recommendation statement. Ann Intern Med. 2012;157(5):373-378.

[27] STOP (Strategies to Overcome and Prevent Obesity) Obesity Alliance. Weight in America Survey. Harris Interactive. 2010

[28] Kushner RF, Butsch WS, Kahan S. Obesity Coverage on Medical Licensing Examinations in the United States. What Is Being Tested? Teach Learn Med. 29 December 2016. doi: 10.1080/10401334.2016.1250641. 